\title{
Review of the treatment of acute coronary syndrome in elderly patients
}

This article was published in the following Dove Press journal:

Clinical Interventions in Aging

16 November 2009

Number of times this article has been viewed

\author{
Maan Jokhadar \\ Nanette K Wenger \\ Division of Cardiology Emory \\ University School of Medicine \\ Atlanta, GA
}

Correspondence: Maan Jokhadar, MD Instructor of Medicine - Division of Cardiology, Adult Congenital Heart Center, 1365 A Clifton Road, NE - Suite A2447 Atlanta, GA 30322, USA Emailmjokhad@emory.edu

\begin{abstract}
Advances in treatment and early revascularization have led to improved outcomes for patients with acute coronary syndrome (ACS). However, elderly ACS patients are less likely to receive evidence-based treatment, including revascularization therapy, due to uncertainty of the associated benefits and risks in this population. This article addresses key issues regarding medical and revascularization therapy in elderly ACS patients based on a review of the medical literature and in concordance with clinical practice guidelines from the American Heart Association (AHA) and the American College of Cardiology (ACC).
\end{abstract}

Keywords: acute coronary syndrome, revascularization, medical therapy

\section{Background}

ACS is most commonly caused by coronary atherosclerotic plaque rupture and subsequent intracoronary thrombus formation, which leads to myocardial ischemia. If coronary blood flow is interrupted long enough, myocyte necrosis (infarction) can occur.

The clinical presentation of ACS is variable, but typically includes chest pain. The classical description is retrosternal chest discomfort that radiates to the jaw and left arm, which can be associated with dyspnea, diaphoresis, nausea, or vomiting. Elderly ACS patients are less likely to present with typical symptoms as discussed in this article. Hemodynamic decompensation can occur due to ventricular arrhythmias or to severe myocardial dysfunction.

The electrocardiogram (ECG) and cardiac biomarkers (such as troponin) are useful for diagnosis and risk stratification and thus can guide treatment. ${ }^{1-3}$

The 2007 Joint Task Force of the European Society of Cardiology, American College of Cardiology Foundation, the American Heart Association, and the World Heart Federation (ESC/ACCF/AHA/WHF) redefined acute myocardial infarction (MI) as the death of cardiac myocytes that is caused by ischemia and not by other etiologies such as inflammation or trauma. ${ }^{4}$

ACS can be divided into two categories: ST-elevation myocardial infarction; unstable angina and non-ST-elevation myocardial infarction.

\section{ST-elevation myocardial infarction}

ST-elevation myocardial infarction (STEMI) is caused by complete occlusion of the culprit artery in $>80 \%$ of cases. ${ }^{5,6}$ STEMI is diagnosed in the presence of ischemic chest pain (or equivalent) when the ECG shows new ST-segment elevation at the 
J-point in 2 contiguous leads with the cut-off points of $\geq 0.2$ $\mathrm{mV}$ in men or $\geq 0.15 \mathrm{mV}$ in women, in leads V2 and V3 and/or $\geq 0.1 \mathrm{mV}$ in other leads. ${ }^{4}$

STEMI also includes new or presumed-new left bundle branch block (LBBB), a finding more common in the elderly. True posterior MI should be suspected when the ECG shows ST segment depression in leads V1 through V4 and can be differentiated from anterior ischemia by obtaining an ECG with posterior leads (V7 and V8), which reveals ST segment elevation in the presence of a posterior MI. ${ }^{2,3}$

Cardiac biomarkers are elevated in STEMI but are not necessary for the initial diagnosis. Revascularization should be initiated immediately based on the clinical presentation and ECG findings and should not be delayed until cardiac biomarker results are available. Cardiac biomarker values are often normal during the first few hours of STEMI.

In addition to standard ancillary ACS therapy, the primary goal of treatment in STEMI, within 12 hours of symptom onset, is rapid revascularization with either thrombolysis in the absence of contraindications, or preferably, emergent percutaneous coronary intervention (PCI), when available., ${ }^{2,3}$ The earlier the revascularization, the better the outcome (time is muscle).

Standard ancillary ACS therapy includes oxygen, antiplatelet agents (aspirin \pm clopidogrel and/or glycoprotein IIb/IIIa inhibitors), nitrates, beta-blockers, anticoagulants (heparin, bivalirudin, or fondaparinux), and statins..$^{1-3}$

\section{Unstable angina and non-ST elevation myocardial infarction}

Unstable (UA) and and non-ST elevation myocardial infarction (NSTEMI) are grouped together as they are caused by incomplete occlusion of the culprit artery in 60\% to $90 \%$ of cases. ${ }^{7-10}$ Normal cardiac biomarkers are seen in UA which differentiates it from NSTEMI, which has elevated cardiac biomarkers. The primary presenting symptom is ischemic chest pain (or equivalent). The ECG may be normal but may show ischemic changes, which include: new horizontal or down-sloping ST depression $\geq 0.05 \mathrm{mV}$ in 2 contiguous leads and/or T-wave inversion $\geq 0.1 \mathrm{mV}$ in 2 contiguous leads with prominent $\mathrm{R} / \mathrm{S}$ ratio $>1 .^{4}$

In addition to standard ACS therapy, primary PCI is preferred in most UA/NSTEMI patients, especially those in higher risk categories. Primary PCI is usually less urgent for UA/NSTEMI than in STEMI due to higher culprit artery patency rates and typically can be performed within 48 hours of symptom onset. ${ }^{1}$ Thrombolysis is contraindicated in UA/NSTEMI due to lack of benefit and increased risk of complications. This may be due to different culprit artery patency rates as well as different pathophysiological processes between STEMI and UA/NSTEMI, including differences in thrombus composition and mechanisms of ischemia. ${ }^{10-12}$ Treatment of UA/NSTEMI in elderly patients is discussed in detail below.

\section{Acute coronary syndrome in the elderly}

Despite the enormity of published information regarding the treatment of ACS, there is a paucity of data to guide the evaluation and management of ACS in the elderly, as only a minority of published clinical trials included elderly patients. Even when elderly patients are enrolled in clinical trials, they typically account only for a disproportionately small number of the study population and age-subset-specific results are often not reported. ${ }^{4,5}$ Indeed, patients above 75 years of age comprise only $9 \%$ of clinical trial populations and only about $50 \%$ of trials enroll patients above the age of $75 .{ }^{6}$ Data guiding coronary reperfusion in elderly ACS patients are limited and comprise mostly of subset analyses from major trials and retrospective studies. ${ }^{7}$ Thus, information is sparse to guide the care of this high risk ACS subset.

Approximately $33 \%$ of all ACS episodes occur in patients over 75 years and account for about $60 \%$ of overall mortality due to ACS. ${ }^{13-15}$ The incidence of ACS in the elderly is projected to increase due to advances in prior ACS treatment in an aging population. ${ }^{16,17}$

Chest pain is the most common presenting symptom of ACS in all age subgroups. However, elderly ACS patients often present with atypical symptoms; meaning that ischemic pain is either absent or is in an atypical location, such as the abdomen. Dyspnea is a common presenting symptom. ${ }^{18-20}$ In addition, ACS in the elderly can often be precipitated by hemodynamic stressors such as infection or dehydration. ${ }^{21,22}$ Therefore, a high index of suspicion is needed to diagnose ACS in the elderly. Atypical presentation of ACS in elderly patients may delay diagnosis and treatment, which may in turn contribute to worse outcomes. ${ }^{18}$

Elderly ACS patients are more likely to have comorbid conditions such as diabetes mellitus, renal insufficiency, cerebrovascular disease, and heart failure. Limited functional capacity and dementia are also more common and these factors must be taken into account in management decisions for these patients..$^{21,22}$

Medication side effects are more common in elderly patients due to differences in drug absorption, metabolism, distribution, and excretion. Therefore, special attention must 
be directed to avoid adverse drug interactions as well as ensuring appropriate medication dose adjustment according renal function. ${ }^{21,22}$

Although imperfect, the most commonly used method for calculating creatinine clearance is the Cockroft and Gault formula, which takes into account age, weight, gender, and serum creatinine. ${ }^{23}$

Creatinine clearance $(\mathrm{mL} / \mathrm{min})=\{(140-$ age $[\mathrm{yr}]) \times$ lean body weight $(\mathrm{kg})\} /(72 \times$ serum creatinine $[\mathrm{mg} / \mathrm{dL}])$.

For women, the formula requires multiplication by 0.85 to account for smaller muscle mass compared to men.

Adverse events are more common in elderly ACS patients. The complication rates of PCI, thrombolysis, anticoagulation, and antiplatelet therapies exceed that observed in younger patients. However, elderly ACS patients are also more likely to benefit from appropriate therapies, owing to their higher risk status. ${ }^{21-22}$

Treatment for ACS can be divided into revascularization therapy and ancillary therapy.

\section{Revascularization therapy ST elevation myocardial infarction Primary $\mathrm{PCl}$ versus thrombolytics}

PCI is more effective than thrombolytics in vessel opening and in restoring normal (Thrombolysis in Myocardial Infarction [TIMI] grade 3) coronary blood flow. PCI is associated with less recurrent ischemia and thrombotic coronary reocclusion than thrombolytic therapy. PCI is overall safer and associated with less intracerebral hemorrhage. Lastly, PCI appears to improve both short- and long-term survival in elderly STEMI patients. A major challenge is the limited availability of primary PCI.

Data from the GUSTO IIb trial showed that primary PCI was superior to thrombolysis in all age subgroups, with elderly patients deriving the most benefit. ${ }^{24} \mathrm{~A}$ metaanalysis that included 10 trials comparing thrombolysis with PCI showed that 30-day mortality in patients over 70 years was halved in the PCI group compared to thrombolysis. ${ }^{25}$ Again, elderly patients derived the greatest benefit compared to their younger counterparts. In two retrospective analyses of Medicare STEMI in patients aged $\geq 65$ years, primary PCI was superior to both thrombolysis and medical therapy in reducing both, 30-day mortality and 1-year mortality. ${ }^{26,27}$ The risk of major bleeding, including intracerebral hemorrhage, is increased with thrombolytic use compared to PCI.

As mentioned previously, PCI with stenting is superior to PCI without stenting in all age subgroups, including the elderly. ${ }^{28,29}$ Data from the CADILLAC trial show that PCI with stenting improved the composite endpoint of death, reinfarction, disabling stroke, and ischemia-driven target vessel revascularization at 6 months ${ }^{28}$ and 12 months. ${ }^{29}$ The benefit of stenting was primarily from reduced ischemiadriven revascularization of the target vessel during follow-up (7.0\% vs $17.6 \%)$.

In a clinical trial from the Netherlands, primary PCI was compared to streptokinase in 87 patients with acute STEMI over the age of $75 .{ }^{30}$ This trial was terminated prematurely owing to overwhelming benefit, albeit in a small cohort. Primary PCI was superior to streptokinase in reducing the primary endpoint of death, reinfarction, or stroke at 30 days ( $9 \%$ vs $29 \%)$ and at 1 year (13\% vs $44 \%)$ of follow-up. Mortality at 1 year was far less with PCI than with streptokinase ( $11 \%$ vs $29 \%$ ).

Thrombolytics, though less preferable to PCI, improve outcomes in elderly STEMI patients compared to lack of revascularization. ${ }^{31,32}$ A pooled analysis of 28896 patients from the GISSI-1 and ISIS-2 trials showed that thrombolytics were associated with a survival benefit in elderly STEMI patients. ${ }^{33}$ One retrospective study of 7864 Medicare patients between the ages of 65 to 86 years failed to show that thrombolytics improved survival in STEMI patients older than 75 years. ${ }^{34}$ The consensus, as described in the ACC/AHA guidelines, is that thrombolytics should be used for elderly STEMI patients in the absence of contraindications if PCI is not promptly available. ${ }^{2,3}$

The goal of treatment in STEMI is to accomplish reperfusion as soon as possible. The earlier the reperfusion occurs, the greater the degree of myocardial salvage and the better the prognosis (time is muscle).

The ACC/AHA guidelines recommend reperfusion within 12 hours of symptom onset with either thrombolytics, or preferably PCI when available. Thrombolytics can be administered up to 24 hours after symptom onset in the presence of persistent symptoms AND persistent ST-elevation in 2 contiguous ECG leads, new or presumed-new LBBB, or true posterior MI.

If the patient presents to a PCI-capable facility, PCI should be performed within 90 minutes of patient presentation (door-to-balloon time). If the patient presents to a non-PCIcapable facility, thrombolytics should be administered within 30 minutes of presentation (door-to-needle time). In elderly patients, transfer from non-PCI-capable facility to PCI-capable facility should be performed if there are contraindications to thrombolysis, failed thrombolysis, or if PCI can be performed at the accepting facility within 
90 minutes of presentation to the first facility. ${ }^{2-3}$ Contemporary data show that, when a patient transfer for primary PCI is required, the 90 minute door-to-balloon time is only achieved in $4 \%$ to $5 \%$ of cases. ${ }^{35}$ These guidelines should not be regarded as hard and fast rules. Clinical judgment and the assessment of the logistics of care, play a critical role.

Of the thrombolytics, more fibrin specific agents such as tenecteplase or alteplase (genetically modified tissue plasminogen activator[tPA]) are preferred due to reduced risk of bleeding. ${ }^{36}$ When compared to alteplase, tenecteplase was associated with a $1.9 \%$ reduction (1.1 vs $3.0 \%)$ in intracerebral hemorrhage in elderly women who weighed less than $67 \mathrm{~kg} .{ }^{37}$ Ease of administration is an added advantage of tenecteplase.

Intracerebral hemorrhage is a devastating complication of thrombolytics and occurs in about $1.4 \%$ of patients older than 65 years of age.$^{38}$ When intracerebral hemorrhage occurs in this setting, it is usually lethal or disabling. ${ }^{39,40}$ Risk factors for intracerebral hemorrhage include: age $>75$ years, black race, and low body weight $(<65 \mathrm{~kg}$ in woman and $<80 \mathrm{~kg}$ in men). Systolic blood pressure $>160 \mathrm{mmHg}$, and international normalized ratio (INR) $>4$ are additional risk factors and are listed as contraindications to thrombolytic administration (Table 1).
Ventricular free wall rupture is another feared complication of thrombolytics. Approximately 17.1\% elderly STEMI patients treated with thrombolytics have free wall rupture, compared to $7.9 \%$ of patients who do not receive reperfusion, and $4.9 \%$ of patients treated with PCI. Free wall rupture accounts for about $50 \%$ of deaths after thrombolytics. ${ }^{39}$ Eligible elderly STEMI patients often do not receive thrombolytics, in part, because of the fear of causing complications and in part, because of uncertainty about the benefit. ${ }^{39,40}$ However, only a minority of elderly STEMI patients are eligible candidates for thrombolytics as contraindication frequency increases with advanced age. ${ }^{21,22}$

\section{Unstable angina and non-ST elevation myocardial infarction Early invasive strategy versus ischemia-guided strategy}

For UA/NSTEMI, management depends on patient risk and can be divided into an early invasive strategy or an ischemia-guided strategy. Early invasive strategy refers to routine cardiac catheterization within 48 hours of presentation. Ischemia-guided strategy refers to cardiac catheterization only

Table I Contraindications and cautions for thrombolysis in STEMI

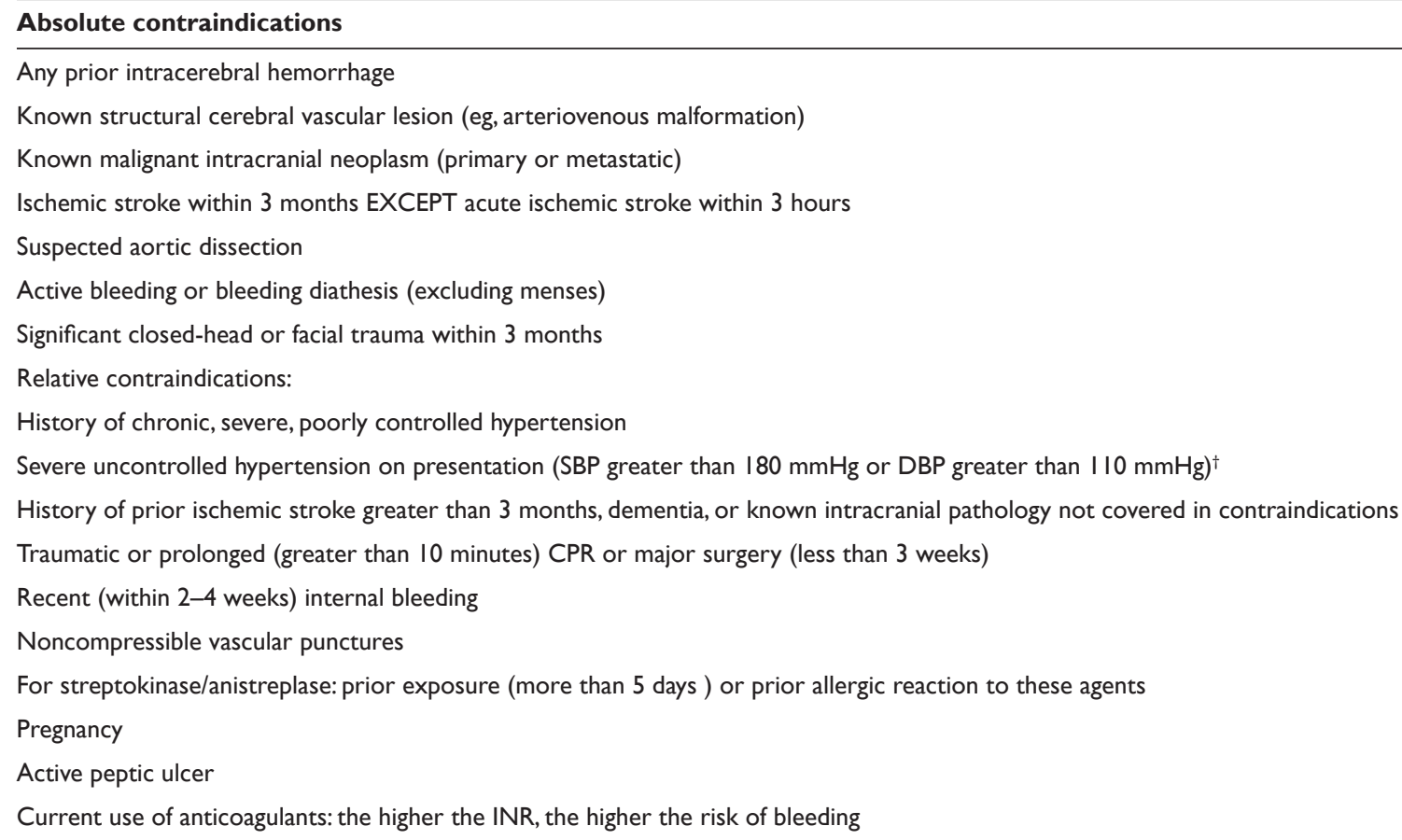

Abbreviations: ICH, intracranial hemorrhage; SBP, systolic blood pressure; DBP, diastolic blood pressure; CPR, cardiopulmonary resuscitation; INR, international normalized ratio; MI, myocardial infarction.

Adapted with permission from Antman EM, Anbe DT, Armstrong PW, et al. ACC/AHA guidelines for the management of patients with ST-elevation myocardial infarction: executive summary: a report of the ACC/AHA Task Force on Practice Guidelines (Committee to Revise the 1999 Guidelines for the Management of Patients With Acute Myocardial Infarction). JAm Coll Cardiol. 2004;44:67I-719. ${ }^{2}$ Copyright (C) 2004 Elsevier. 
in the presence of a positive stress test or recurrent ischemic symptoms. Early invasive strategy is used less frequently in elderly ACS patients. ${ }^{21,22}$ As with other therapies, this may be related to fear of causing complications and uncertainty regarding the benefits of invasive procedures in elderly ACS patients. Owing to their higher risk, elderly ACS patients derive greater benefit from an early invasive strategy than their younger counterparts; in UA/NSTEMI patients aged more than 65 years, an early invasive strategy compared to a conservative strategy significantly reduced the incidence of death or MI at 30 days (5.7\% vs $9.8 \%)$ and six months $(8.8 \%$ vs $13.6 \%$ ). In UA/NSTEMI patients $>75$ years of age, the benefit from an early invasive strategy was even greater in reducing the incidence of death or MI at 6 months $(10.8 \%$ vs $21.6 \%$ ). However, the risk of major bleeding associated with an early invasive strategy increased with advancing age $(16.6 \%$ vs $6.5 \%){ }^{41}$

The ACC/AHA guidelines recommend an early invasive strategy in ACS patients with high-risk indicators. On balance, early invasive strategy provides greater absolute and relative benefit to elderly patients compared with younger patients, despite their higher risk of associated major bleeding. ${ }^{10,21,22}$

It is important to determine patient preference to guide the choice of treatment strategy, realizing that this often depends on the strength of the treating physicians' recommendations.

\section{Estimation of level of risk}

Several risk assessment tools have been used to predict outcomes in ACS. The most commonly used tools are the TIMI risk score for UA/NSTEMI ${ }^{42}$ and the Global Registry of Acute Coronary Events (GRACE) predictive score for ACS: ${ }^{43}$ Worthy of emphasis is the contribution of advanced age to increased risk status in all scores.

The TIMI risk score for UA/NSTEMI, predicts the risk of death or cardiovascular events within 14 days ${ }^{42}$ and is determined by the sum of the presence of 7 variables on admission. These variables are: age $\geq 65$ years, $\geq 3$ coronary risk factors, known coronary stenosis of $\geq 50 \%$, ST segment depression on ECG, $\geq 2$ anginal events within 24 hours, aspirin use, and abnormal levels of cardiac biomarkers. The more the sum of these variables, the greater the risk of death or ischemic events within 14 days after UA/NSTEMI. ${ }^{42}$

The GRACE predictive score is also commonly used to predict the risk of death within 6 months after ACS. ${ }^{43}$ The GRACE score uses a point system encompassing the variables of age, heart failure, previous MI, heart rate, systolic blood pressure, ST segment depression on ECG, serum creatinine, abnormal cardiac biomarkers, and the availability of in-hospital PCI. Higher scores predict higher risks of death within 6 months of ACS. ${ }^{43}$

These risk assessment tools are useful in the management of UA/NSTEMI as higher risk patients would be more likely to benefit from CCU admission, glycoprotein IIb/IIIa inhibitors, and an early invasive strategy. ${ }^{1}$

\section{Ancillary ACS treatment Aspirin}

In the absence of contraindications, all ACS patients should receive 162 to $325 \mathrm{mg}$ of chewable aspirin immediately, if ACS is suspected. ${ }^{1-3,44}$ Nonenteric-coated aspirin is preferable due to quicker antiplatelet inhibition. ${ }^{45}$ With the exception of patients treated with primary PCI, the recommended daily aspirin dose after the first 24 hours is 75 to $162 \mathrm{mg}$ /day thereafter.

For ACS patients treated with PCI, aspirin should be prescribed as follows: 44

Bare-metal stent: aspirin 162 to $325 \mathrm{mg}$ daily for at least 1 month and then 75 to $162 \mathrm{mg}$ thereafter.

Sirolimus-eluting stent: aspirin 162 to $325 \mathrm{mg}$ daily for at least 3 months and then 75 to $162 \mathrm{mg}$ indefinitely thereafter. Paclitaxel-eluting stent: aspirin 162 to $325 \mathrm{mg}$ daily for at least 6 months and then 75 to $162 \mathrm{mg}$ thereafter.

In clinical practice, zotarolimus- or everolimus-eluting stents are treated like sirolimus-eluting stents, but this has not yet been addressed in the guidelines.

\section{Clopidogrel}

In elderly STEMI patients who receive thrombolytics, a loading dose of clopidogrel is not recommended due to increased risk of intracerebral hemorrhage A loading dose of clopidogrel is recommended in elderly STEMI patients only if primary PCI is performed. The recommended dose is $600 \mathrm{mg}$ orally, before or at the time of PCI, which produces rapid antiplatelet activity. For UA/NSTEMI, an oral loading dose of $300 \mathrm{mg}$ is recommended at the time of presentation. ${ }^{1-3}$

If PCI is not performed, a daily dose of clopidogrel $75 \mathrm{mg}$ should be continued, in addition to indefinite aspirin, for at least 14 days in STEMI, ${ }^{2,3}$ and for 9 to 12 months in UA/NSTEMI. ${ }^{1}$

If PCI with bare-metal stent is performed, a daily dose of clopidogrel $75 \mathrm{mg}$ should be continued for at least 1 month and preferably up to 12 months. For PCI with a drug-eluting stent, clopidogrel $75 \mathrm{mg}$ should be continued daily for at least 
12 months. Prolonged dual antiplatelet therapy is required for drug-eluting stents due to delayed stent endothelialization associated with the antiproliferative effects of the eluted drugs (sirolimus, paclitaxel, zotarolimus, or everolimus). Dual antiplatelet therapy is continued until the stent has time for complete endothelialization, to prevent stent thrombosis. Aspirin should be continued indefinitely, and without interruption, due to the persistent risk of stent thrombosis. ${ }^{1-3,44}$

For both, bare-metal and drug-eluting stents, the risk of stent thrombosis within the first year is very low as long as dual antiplatelet therapy is continued. ${ }^{46-48}$ However, the risk of stent thrombosis after the first year appears to be higher in drug-eluting stents compared to bare-metal stents. ${ }^{49}$ This has been an area of controversy and received much publicity in the press. On balance, it is important to consider that the risk of stent thrombosis associated with drug-eluting stents after the first year is between $0.6 \%$ to $0.9 \%$ (cumulative risk), which is increased by $0.3 \%$ to $0.6 \%$ when compared to bare-metal stents. ${ }^{50,51}$ This should be balanced against the higher risk of early restenosis in patients who receive baremetal stents. More important, no difference in mortality has been demonstrated between bare-metal and drug-eluting stents $^{48,50,52}$

\section{Glycoprotein Ilb/Illa inhibitors}

The ACC/AHA guidelines recommend the use of glycoprotein IIb/IIIa inhibitors in high-risk NSTEMI patients, if PCI is planned, without modification based on age. ${ }^{1}$ Appropriate dose adjustment based on renal function is emphasized. In STEMI, the use of glycoprotein IIb/IIIa inhibitors is reasonable prior to PCI. However, glycoprotein IIb/IIIa inhibitors play a secondary role in STEMI where early revascularization is the primary objective.

\section{Antithrombin therapy}

In the absence of contraindications, the ACC/AHA guidelines recommend the use of either unfractionated heparin or low molecular weight heparin in patients with ACS without modification based on age. ${ }^{1-3}$ Appropriate dose adjustment to weight and renal function is emphasized to reduce bleeding complications. Newer agents such as fondaparinux and bivalarudin may provide theoretical advantages, but data regarding their use in elderly ACS patients are limited.

\section{Morphine}

Morphine is a potent analgesic, anxiolytic, and venodilator, which may help reduce heart rate and myocardial oxygen demand in the setting of ACS. Despite the absence of clinical trial evidence, morphine use has long been a Class I recommendation in the treatment of ACS. However, recent registry data indicate a possible increase in adverse outcomes associated with morphine use. For UA/NSTEMI, morphine use was downgraded to a Class IIa recommendation, but remains a class I recommendation for STEMI. ${ }^{1-3,53}$ Clinical trials are needed to establish the role of morphine in ACS patients in general and in elderly ACS patients in particular.

\section{Beta-blockers}

Oral beta-blockers reduce infarct progression and improve both long-term and short-term outcomes. Except in hemodynamically unstable patients, the magnitude of benefit from early beta-blocker use appears to be greater in the elderly, compared to younger ACS patients. Intravenous beta-blocker use is discouraged (Class III in 2007 ACC/AHA guideline), ${ }^{1}$ although their early use was advocated in previous ACC/AHA guideline statements (Class IIa in 2004). This is due to the higher risk of hemodynamic compromise and bradycardia associated with intravenous beta-blocker use, which may be more profound in elderly patients. The initial use of a short-acting oral beta blocker is currently preferred. ${ }^{1-3,21,22,53}$

\section{Angiotensin converting enzyme (ACE) inhibitors and angiotensin receptor blockers (ARBs)}

Long-term treatment with ACE inhibitors after myocardial infarction is associated with improved outcomes, especially in patients with left ventricular systolic ejection fraction less than $40 \%$. Elderly ACS patients appear to derive greater benefit from ACE inhibitors than their younger counterparts. ARBs should be used as an alternative in ACE inhibitor intolerant patients. ACE inhibitors and ARBs are not part of the initial management of ACS patients and should not be started until the patient is stabilized and is ready for hospital discharge. Renal function and electrolytes should be monitored closely, especially in elderly patients. ${ }^{1-3,54-58}$

\section{Aldosterone blockade}

Aldosterone blockade with eplerenone in addition to standard therapy after myocardial infarction improves outcomes in a broad range of ACS patients with left ventricular dysfunction. ${ }^{59}$ However, a high incidence of renal failure and hyperkalemia has been observed in patients above the age of 65 years. The use of spironolactone has not been 
studied in the setting of ACS in the elderly. Therefore, caution should be used when prescribing spironolactone or eplerenone in elderly ACS patients. The patient's electrolytes and renal function should be monitored closely in follow-up. Aldosterone blockade is not part of the initial management and should not be started until the patient is stabilized and in preparation for hospital discharge.

\section{Nitrates}

Nitrates are recommended by the ACC/AHA guidelines as part of the initial management of both STEMI and UA/ NSTEMI. Nitrates can provide symptomatic relief in ACS but are not associated with a survival benefit in younger ACS patients. However, nitrate use in the elderly ACS patients is associated with a reduction in mortality, heart failure, and left ventricular dysfunction at 6 months follow-up. ${ }^{1-3,54,55}$

\section{Lipid-lowering therapy}

The ACC/AHA guidelines recommend lipid-lowering therapy to achieve a target low-density lipoprotein level $<100 \mathrm{mg} / \mathrm{dL}$ with consideration to lowering to $<70 \mathrm{mg} / \mathrm{dL}$. This is without modification based on age. ${ }^{1-3}$ Preference is given to HMG-CoA reductase inhibitors (statins) as their early use in ACS associated with greater short and long-term benefit, which appears to be greater in the elderly ACS patients compared to their younger counterparts. Statins may improve outcomes by other mechanisms in addition to lipid-lowering, including anti-inflammatory effects. ${ }^{1-3,60-63}$

\section{Cardiac rehabilitation and secondary prevention}

The ACC/AHA guidelines recommend that all ACS patients enroll in cardiac rehabilitation/secondary prevention programs, when available. ${ }^{1-3}$ Cardiac rehabilitation allows for monitored, supervised, and graduated exercise under medical supervision and has been shown to reduce the risk of sudden death and recurrent MI. Cardiac rehabilitation also provides psychological benefits to the ACS patient. ${ }^{64,65}$ Longterm survival may also be improved in cardiac rehabilitation participants. ${ }^{66}$

Secondary prevention refers to preventing recurrence of ACS, which can be reduced by treating all modifiable risk factors, including smoking cessation, weight reduction, treatment of diabetes mellitus, and precise blood pressure and lipid control. Fish oil supplementation (omega-3 fatty acids) is also recommended as this has been shown to reduce the risk of sudden death in patients with a history of myocardial infarction. ${ }^{67,68}$

\section{Coronary artery bypass graft surgery}

Advanced age is associated with higher morbidity and mortality in patients undergoing coronary artery bypass graft CABG. ${ }^{69}$ Earlier studies reported prohibitive CABG-related mortality rates in patients over the age of 70 years. ${ }^{70}$ This led some to believe that advanced age was a contraindication to $\mathrm{CABG}$. More recent reports show improved outcomes after CABG in the elderly despite the increased severity of coronary artery disease and increased frequency of comorbid medical conditions in this population. ${ }^{71}$ Therefore, patients over the age of 70 years should not be denied CABG solely on the basis of age, as satisfactory recovery is possible in the majority of elderly patients undergoing CABG. ${ }^{69}$ Indeed, select elderly patients have been shown to benefit from emergent $\mathrm{CABG}$ even in the setting of cardiogenic shock. ${ }^{72}$

Caution is advised before reaching the decision to recommend $\mathrm{CABG}$ in the elderly, with particular attention warranted to baseline functional capacity, comorbid medical conditions, and patient preference. $\mathrm{CABG}$ is reasonable if the long-term benefits outweigh the procedural risk of CABG. ${ }^{69}$

In elderly patients with indications for $\mathrm{CABG}$, some evidence suggests that off-pump surgery, when available, may be preferable to on-pump surgery; in patients over the age of 70 years, off-pump bypass grafting is associated with a lower incidence of stroke, atrial fibrillation, as well as shorter mechanical ventilation times when compared to on-pump bypass grafting. No mortality benefit has been demonstrated for off-pump bypass grafting versus traditional CABG. ${ }^{73-75}$

\section{Challenges and ethical concerns}

Caring for the critically ill elderly patient can pose a unique set of practical challenges and ethical dilemmas. Cognitive impairment, communication difficulties, frailty, comorbid medical illnesses, and the patient's family dynamics are but a few factors that must be taken into account when caring for the elderly ACS patient.

As with all physician-patient interactions, one must always apply the four main ethical principles of autonomy, beneficence, nonmaleficence, and justice, when caring for the elderly ACS patient.

1) Autonomy is to respect the patient's right to self determination. Understanding the patient's wishes can be challenging in the presence of cognitive impairment.

2) Beneficence is doing good for the patient and acting in their best interest, which may not always be clear due to the potential trade-off between quality and quantity of life. 
3) Nonmaleficence is the principle of avoiding harm to the patient and is embodied by the phrase "do no harm". This principle is not absolute and must be balanced against the principle of beneficence.

4) Justice is the principle of equitable allocation of medical resources and providing similar care for all. Potentially beneficial treatments are often withheld from elderly patients solely on the basis of advanced age. The principle of justice must be balanced against the need to control healthcare costs and the limited availability of resources. These principles should not be regarded as inflexible rules but as a framework to aid in the decision-making process in complex medical and ethical situations. The physician must have a clear understanding of ACS management, specifically regarding the associated benefits and risks of ACS treatments. Treatment decisions should be made after discussion with the patient (or surrogate) regarding the plan of care and one must be cognizant of the influence of the physician's personal bias on the patient's decisions.

\section{Disclosures}

The authors report no conflicts of interest in this work.

\section{References}

1. Anderson JL, Adams CD, Antman EM, et al. ACC/AHA 2007 guidelines for the management of patients with unstable angina/non-STElevation myocardial infarction: a report of the American College of Cardiology/American Heart Association Task Force on Practice Guidelines (Writing Committee to Revise the 2002 Guidelines for the Management of Patients With Unstable Angina/Non-ST-Elevation Myocardial Infarction) developed in collaboration with the American College of Emergency Physicians, the Society for Cardiovascular Angiography and Interventions, and the Society of Thoracic Surgeons endorsed by the American Association of Cardiovascular and Pulmonary Rehabilitation and the Society for Academic Emergency Medicine. J Am Coll Cardiol. 2007 Aug 14;50(7):e1-e157.

2. Antman EM, Anbe DT, Armstrong PW, et al. ACC/AHA guidelines for the management of patients with ST-elevation myocardial infarction: executive summary: a report of the ACC/AHA Task Force on Practice Guidelines (Committee to Revise the 1999 Guidelines for the Management of Patients With Acute Myocardial Infarction). JAm Coll Cardiol. 2004;44:671-719.

3. Antman EM, Hand M, Armstrong PW, et al. 2007 Focused Update of the ACC/AHA 2004 Guidelines for the Management of Patients With ST-Elevation Myocardial Infarction: a report of the American College of Cardiology/American Heart Association Task Force on Practice Guidelines: developed in collaboration With the Canadian Cardiovascular Society endorsed by the American Academy of Family Physicians: 2007 Writing Group to Review New Evidence and Update the ACC/AHA 2004 Guidelines for the Management of Patients With ST-Elevation Myocardial Infarction, Writing on Behalf of the 2004 Writing Committee. Circulation. 2008 Jan 15;117(2):296-329.

4. Thygesen K, Alpert JS, White HD, et al. Universal definition of myocardial infarction: Kristian Thygesen, Joseph S. Alpert and Harvey D. White on behalf of the Joint ESC/ACCF/AHA/WHF Task Force for the Redefinition of Myocardial Infarction. Eur Heart J. 2007 Oct;28(20):2525-2538.
5. DeWood MA, Spores J, Notske R, et al. Prevalence of total coronary occlusion during the early hours of transmural myocardial infarction. N Engl J Med. 1980 Oct 16;303(16):897-902.

6. DeWood MA, Spores J, Hensley GR, et al. Coronary arteriographic findings in acute transmural myocardial infarction. Circulation. 1983 Aug;68(2 Pt 2):I39-49.

7. Liebson PR, Klein LW. The non-Q wave myocardial infarction revisited: 10 years later. Prog Cardiovasc Dis. 1997 Mar-Apr;39(5):399-444.

8. Early effects of tissue-type plasminogen activator added to conventional therapy on the culprit coronary lesion in patients presenting with ischemic cardiac pain at rest. Results of the Thrombolysis in Myocardial Ischemia (TIMI III A) Trial. Circulation. 1993 Jan;87(1):38-52.

9. Kerensky RA, Wade M, Deedwania P. Revisiting the culprit lesion in non-Q-wave myocardial infarction. Results from the VANQWISH trial angiographic core laboratory. J Am Coll Cardiol. 2002 May 1;39(9):1456-1463.

10. Wong GC, Morrow DA, Murphy S, et al. Elevations in troponin T and I are associated with abnormal tissue level perfusion: a TACTICSTIMI 18 substudy. Treat Angina with Aggrastat and Determine Cost of Therapy with an Invasive or Conservative Strategy-Thrombolysis in Myocardial Infarction. Circulation. 2002 Jul 9;106(2):202-207.

11. Jang IK, Gold HK, Ziskind AA, et al. Differential sensitivity of erythrocyte-rich and platelet-rich arterial thrombi to lysis with recombinant tissue-type plasminogen activator. A possible explanation for resistance to coronary thrombolysis. Circulation. 1989 Apr;79(4):920-928.

12. Mizuno K, Satomura K, Miyamoto A, et al. Angioscopic evaluation of coronary-artery thrombi in acute coronary syndromes. $N$ Engl J Med. 1992 Jan 30;326(5):287-291.

13. Alexander KP, Roe MT, Chen AY, et al. CRUSADE Investigators. Evolution in cardiovascular care for elderly patients with non-ST-segment elevation acute coronary syndromes: results from the CRUSADE National Quality Improvement Initiative. J Am Coll Cardiol. 2005;46:1479-1487.

14. Goldberg RJ, McCormick D, Gurwitz JH, et al. Age-related trends in short- and long-term survival after acute myocardial infarction: a 20-year population-based perspective (1975-1995). Am J Cardiol. 1998 Dec 1;82(11):1311-1317.

15. Roger VL, Jacobsen SJ, Weston SA, et al. Trends in the incidence and survival of patients with hospitalized myocardial infarction, Olmsted County, Minnesota, 1979 to 1994. Ann Intern Med. 2002 Mar 5;136(5):341-348.

16. The future of CVD. In: Mackay J, Mensah G, eds. The Atlas of Heart Disease and Stroke. Geneva, Switzerland: World Health Organization; 2004:74-75. Available at: http://www.who.int/cardiovascular_diseases/ en/cvd_atlas_25_future.pdf. Accessed April 19, 2008.

17. CDC. Public health and aging: trends in aging: United States and worldwide. MMWR. 2003;52:101-106.

18. Brieger D, Eagle KA, Goodman SG, et al. GRACE Investigators. Acute coronary syndromes without chest pain, an underdiagnosed and undertreated high-risk group: insights from the Global Registry of Acute Coronary Events. Chest. 2004;126:461-469.

19. Bayer AJ, Chadha JS, Farag RR, et al. Changing presentation of myocardial infarction with increasing old age. J Am Geriatr Soc. 1986 Apr;34(4):263-266.

20. Canto JG, Shlipak MG, Rogers WJ, et al. Prevalence, clinical characteristics, and mortality among patients with myocardial infarction presenting without chest pain. JAMA. 2000;283:3223-3229.

21. Alexander KP, Newby LK, Cannon CP, et al. Acute coronary care in the elderly, part I: Non-ST-segment-elevation acute coronary syndromes: a scientific statement for healthcare professionals from the American Heart Association Council on Clinical Cardiology: in collaboration with the Society of Geriatric Cardiology. Circulation. 2007;115:2549.

22. Alexander KP, Newby LK, Cannon CP, et al. Acute coronary care in the elderly, part II: ST-segment-elevation myocardial infarction: a scientific statement for healthcare professionals from the American Heart Association Council on Clinical Cardiology: in collaboration with the Society of Geriatric Cardiology. Circulation. 2007 May 15; 115(19):2570-2589. 
23. Cockcroft DW, Gault MH. Prediction of creatinine clearance from serum creatinine. Nephron. 1976;16(1):31-41.

24. The Global Use of Strategies to Open Occluded Coronary Arteries in Acute Coronary Syndromes (GUSTO IIb) Angioplasty Substudy Investigators. A clinical trial comparing primary coronary angioplasty with tissue plasminogen activator for acute myocardial infarction. N Engl J Med. 1997;336:1621-1628.

25. Zijlstra F, Patel A, Jones M, et al. Clinical characteristics and outcome of patients with early $(<2 \mathrm{~h})$, intermediate $(2-4 \mathrm{~h})$ and late $(>4 \mathrm{~h})$ presentation treated by primary coronary angioplasty or thrombolytic therapy for acute myocardial infarction. Eur Heart J. 2002;23:550.

26. Berger, AK, Schulman, KA, Gersh, BJ, et al. Primary coronary angioplasty vs thrombolysis for the management of acute myocardial infarction in elderly patients. JAMA. 1999;282:341.

27. Berger AK, Radford MJ, Wang Y, et al. Thrombolytic therapy in older patients. J Am Coll Cardiol. 2000;36:366.

28. Stone GW, Grines CL, Cox DA, et al. Comparison of angioplasty with stenting, with or without abciximab, in acute myocardial infarction. N Engl J Med. 2002;346:957.

29. Guagliumi G, Stone GW, Cox DA, et al. Outcome in elderly patients undergoing primary coronary intervention for acute myocardial infarction: results from the Controlled Abciximab and Device Investigation to Lower Late Angioplasty Complications (CADILLAC) trial. Circulation. 2004;110:1598.

30. de Boer MJ, Ottervanger JP, van't Hof AW, et al. Reperfusion therapy in elderly patients with acute myocardial infarction: a randomized comparison of primary angioplasty and thrombolytic therapy. $J \mathrm{Am}$ Coll Cardiol. 2002;39:1723.

31. Stenestrand U, Wallentin L. Fibrinolytic therapy in patients 75 years and older with ST-segment-elevation myocardial infarction: one-year follow-up of a large prospective cohort. Arch Intern Med. 2003;163: 965-971.

32. Berger AK, Radford MJ, Wang Y, Krumholz HM. Thrombolytic therapy in older patients. J Am Coll Cardiol. 2000;36:366-374.

33. Collins R. Optimizing thrombolytic therapy of acute myocardial infarction: Age is not a contraindication. Circulation. 1991;84:II230.

34. Thiemann DR, Coresh J, Schulman SP, et al. Lack of benefit for intravenous thrombolysis in patients with myocardial infarction who are older than 75 years. Circulation. 2000;101:2239.

35. Nallamothu BK, Bates ER, et al. Times to treatment in transfer patients undergoing primary percutaneous coronary intervention in the United States: National Registry of Myocardial Infarction (NRMI)-3/4 analysis. Circulation. 2005;111:761.

36. Single-bolus tenecteplase compared with front-loaded alteplase in acute myocardial infarction: the ASSENT-2 double-blind randomised trial. Assessment of the Safety and Efficacy of a New Thrombolytic Investigators. Lancet. 1999;354:716.

37. Van de Werf F, Barron HV, Armstrong PW, et al. Incidence and predictors of bleeding events after fibrinolytic therapy with fibrin-specific agents: a comparison of TNK-tPA and rt-PA. Eur Heart J. 2001;22:2253.

38. Brass LM, Lichtman JH, Wang Y, et al. Intracranial hemorrhage associated with thrombolytic therapy for elderly patients with acute myocardial infarction. Results from the Cooperative Cardiovascular Project. Stroke. 2000;31:1802.

39. Gurwitz JH, Gore JM, Goldberg RJ, et al. Risk for intracranial hemorrhage after tissue plasminogen activator treatment for acute myocardial infarction. Ann Intern Med. 1998;129:597.

40. Gore JM, Granger CB, Simoons ML, et al. Stroke after thrombolysis. Mortality and functional outcomes in the GUSTO-I trial. Global Use of Strategies to Open Occluded Coronary Arteries. Circulation. 1995;92:2811.

41. Bach RG, Cannon CP, Weintraub WS, et al. The effect of routine, early invasive management on outcome for elderly patients with nonST-segment elevation acute coronary syndromes. Ann Intern Med. 2004 Aug 3;141(3):186-195.

42. Antman EM, Cohen M, Bernink PJ, et al. The TIMI risk score for unstable angina/non-ST elevation MI: a method for prognostication and therapeutic decision making. JAMA. 2000;284:835-842.
43. Eagle KA, Lim MJ, Dabbous OH, et al. A validated prediction model for all forms of acute coronary syndrome: estimating the risk of 6-month postdischarge death in an international registry. JAMA. 2004;291: $2727-2733$.

44. King SB III, Smith SC Jr, Hirshfeld JW Jr, et al. 2007 focused update of the ACC/AHA/SCAI 2005 guideline update for percutaneous coronary intervention: a report of the American College of Cardiology/American Heart Association Task Force on Practice guidelines. J Am Coll Cardiol. 2008 Jan 15;51(2):172-209.

45. Sagar KA, Smyth MR. A comparative bioavailability study of different aspirin formulations using on-line multidimensional chromatography. J Pharm Biomed Anal. 1999;21:383-392.

46. Ellis SG, Colombo A, Grube E, et al. Incidence, timing, and correlates of stent thrombosis with the polymeric paclitaxel drug-eluting stent: a TAXUS II, IV, V, and VI meta-analysis of 3,445 patients followed for up to 3 years. J Am Coll Cardiol. 2007 Mar 13;49(10):1043-1051. Epub $2007 \mathrm{Feb} 26$.

47. Roiron C, Sanchez P, Bouzamondo A, et al. Drug eluting stents: an updated meta-analysis of randomised controlled trials. Heart. 2006 May;92(5):641-649. Epub 2005 Oct 10.

48. Kastrati A, Dibra A, Eberle S, et al. Sirolimus-eluting stents vs paclitaxel-eluting stents in patients with coronary artery disease: meta-analysis of randomized trials. JAMA. 2005 Aug 17;294(7): 819-825.

49. Bavry AA, Kumbhani DJ, Helton TJ, et al. Late thrombosis of drugeluting stents: a meta-analysis of randomized clinical trials. Am J Med. 2006 Dec;119(12):1056-1061.

50. Mauri L, Hsieh WH, Massaro JM ,et al. Stent thrombosis in randomized clinical trials of drug-eluting stents. $N$ Engl J Med. 2007 Mar 8;356(10):1020-1029. Epub 2007 Feb 12.

51. Stone GW, Moses JW, Ellis SG, et al. Safety and efficacy of sirolimus- and paclitaxel-eluting coronary stents. N Engl J Med. 2007 Mar 8;356(10):998-1008. Epub 2007 Feb 12.

52. Spaulding C, Daemen J, Boersma E, et al. A pooled analysis of data comparing sirolimus-eluting stents with bare-metal stents. $N$ Engl $J$ Med. 2007 Mar 8;356(10):989-997. Epub 2007 Feb 12.

53. Chen ZM, Jiang LX, Chen YP, et al. COMMIT (ClOpidogrel and Metoprolol in Myocardial Infarction Trial) collaborative group. Addition of clopidogrel to aspirin in 45852 patients with acute myocardial infarction: randomised placebo-controlled trial. Lancet. 2005;366: 1607-1621.

54. ISIS-4 (Fourth International Study of Infarct Survival) Collaborative Group. ISIS-4: A randomised factorial trial assessing early oral captopril, oral mononitrate, and intravenous magnesium sulphate in 58050 patients with suspected acute myocardial infarction. Lancet. 1995;345:669-685.

55. Gruppo Italiano per lo Studio della Sopravvivenza nell'Infarto Miocardioco. Six-month effects of early treatment with lisinopril and transdermal glyceryl trinitrate singly and together withdrawn six weeks after myocardial infarction: the GISSI-3 Trial. $J$ Am Coll Cardiol. 1996;27:337-344.

56. The Acute Infarction Ramipril Efficacy (AIRE) Study Investigators. Effect of ramipril on mortality and morbidity of survivors of acute myocardial infarction with clinical evidence of heart failure. Lancet. 1993;342:821-828.

57. Dickstein K, Kjekshus J; OPTIMAAL Steering Committee of the OPTIMAAL Study Group. Effects of losartan and captopril on mortality and morbidity in high-risk patients after acute myocardial infarction: the OPTIMAAL randomised trial: Optimal Trial in Myocardial Infarction with Angiotensin II Antagonist Losartan. Lancet. 2002;360: 752-760.

58. White HD, Aylward PE, Huang Y, et al. VALIANT Investigators. Mortality and morbidity remain high despite captopril and/or valsartan therapy in elderly patients with left ventricular systolic dysfunction, heart failure, or both after acute myocardial infarction: results from the Valsartan in Acute Myocardial Infarction Trial (VALIANT) Circulation. 2005;112:3391-3399. 
59. Pitt B, Remme W, Zannad F, et al. Eplerenone, a selective aldosterone blocker, in patients with left ventricular dysfunction after myocardial infarction. N Engl J Med. 2003 Apr 3;348(14):1309-1321. Epub 2003 Mar 31.

60. LaRosa JC, Grundy SM, Waters DD, et al. Intensive lipid lowering with atorvastatin in patients with stable coronary disease. $N$ Engl $J$ Med. 2005 Apr 7;352(14):1425-1435. Epub 2005 Mar 8.

61. Wenger NK, Lewis SJ, Welty FK, et al. Beneficial effects of aggressive LDL cholesterol lowering in women with stable coronary heart disease in the Treating to New Targets (TNT) study. Heart. 2007 Dec 10.

62. Cannon $\mathrm{CP}$, Braunwald $\mathrm{E}, \mathrm{McCabe} \mathrm{CH}$, et al. Intensive versus moderate lipid lowering with statins after acute coronary syndromes. $N$ Engl J Med. 2004 Apr 8;350(15):1495-1504. Epub 2004 Mar 8.

63. Schwartz GG, Olsson AG, Ezekowitz MD, et al. Effects of atorvastatin on early recurrent ischemic events in acute coronary syndromes: the MIRACL study: a randomized controlled trial. JAMA. 2001 Apr 4;285(13):1711-1718.

64. Wenger NK, Froelicher ES, Smith LK, et al. Cardiac rehabilitation as secondary prevention. Agency for Health Care Policy and Research and National Heart, Lung, and Blood Institute. Clin Pract Guidel Quick Ref Guide Clin. 1995;1-23.

65. Balady GJ, Ades PA, Comoss P, et al. Core components of cardiac rehabilitation/secondary prevention programs: a statement for healthcare professionals from the American Heart Association and the American Association of Cardiovascular and Pulmonary Rehabilitation Writing Group. Circulation. 2000;102:1069-1073.

66. Witt BJ, Jacobsen SJ, Weston SA, et al. Cardiac rehabilitation after myocardial infarction in the community. J Am Coll Cardiol. 2004;44: 988-996.

67. Dietary supplementation with n-3 polyunsaturated fatty acids and vitamin E after myocardial infarction: results of the GISSI-Prevenzione trial. Gruppo Italiano per lo Studio della Sopravvivenza nell'Infarto miocardico. Lancet. 1999 Aug 7;354(9177):447-455.
68. Marchioli R, Barzi F, Bomba E, et al. Early protection against sudden death by $n-3$ polyunsaturated fatty acids after myocardial infarction: time-course analysis of the results of the Gruppo Italiano per lo Studio della Sopravvivenza nell‘Infarto Miocardico (GISSI)-Prevenzione. Circulation. 2002 Apr 23;105(16):1897-1903.

69. Eagle KA, Guyton RA, Davidoff R, et al. ACC/AHA 2004 guideline update for coronary artery bypass graft surgery: a report of the American College of Cardiology/American Heart Association Task Force on Practice Guidelines (Committee to Update the 1999 Guidelines for Coronary Artery Bypass Graft Surgery). Circulation. 2004 Oct 5;110(14):e340-e437.

70. Hannan EL, Burke J. Effect of age on mortality in coronary artery bypass surgery in New York, 1991-1992. Am Heart J. 1994;128:1184-91.

71. Ivanov J, Weisel RD, David TE, Naylor CD. Fifteen-year trends in risk severity and operative mortality in elderly patients undergoing coronary artery bypass graft surgery. Circulation. 1998;97:673-680.

72. Hochman JS, Sleeper LA, White HD, et al. for the SHOCK Investigators. Should We Emergently Revascularize Occluded Coronaries for Cardiogenic Shock. One-year survival following early revascularization for cardiogenic shock. JAMA. 2001;285:190-192.

73. Nagpal AD, Bhatnagar G, Cutrara CA, et al. Early outcomes of coronary artery bypass with and without cardiopulmonary bypass in octogenarians. Can J Cardiol. 2006;22:849-853.

74. Athanasiou T, Al-Ruzzeh S, Kumar P, et al. Off-pump myocardial revascularization is associated with less incidence of stroke in elderly patients. Ann Thorac Surg. 2004;77:745-753.

75. Panesar SS, Athanasiou T, Nair S, et al. Early outcomes in the elderly: a metaanalysis of 4921 patients undergoing coronary artery bypass grafting - comparison between off-pump and on-pump techniques. Heart. 2006;92:1808-1816.
Clinical Interventions in Aging

\section{Publish your work in this journal}

Clinical Interventions in Aging is an international, peer-reviewed journal focusing on evidence-based reports on the value or lack thereof of treatments intended to prevent or delay the onset of maladaptive correlates of aging in human beings. This journal is indexed on PubMed Central, MedLine, the American Chemical Society's 'Chemical

\section{Dovepress}

Abstracts Service' (CAS), Scopus and the Elsevier Bibliographic databases. The manuscript management system is completely online and includes a very quick and fair peer-review system, which is all easy to use. Visit http://www.dovepress.com/testimonials.php to read real quotes from published authors. 